\title{
An Overview on the Approaches to Osteoporotic Vertebral Fractures Management
}

\section{Antonio Moroni*}

School of Sports Science, University of Bologna, Italy

\begin{abstract}
Vertebral fractures are the most common fractures in patients with osteoporosis; however, the biggest part of them never comes to clinical attention. Symptoms and secondary deformities can reduce the heath-related quality of life, and increase the risk of mortality. Vertebral fractures can be treated conservatively or surgically by vertebroplasty or kyphoplasty. In this study, we report an overview on the osteoporotic vertebral fractures management, focusing on the most used approaches. Although effectiveness of all these approaches is defined, surgical procedures can lead to higher short-term benefits about relief of pain, improved vertebral body height, physical function and quality of life; the rate cost-effective for vertebroplasty and kyphoplasty appears definitely higher.
\end{abstract}

Keywords: Vertebral fractures; Osteoporosis; Conservative treatment; Surgical treatment

\section{Introduction}

Vertebral fractures are the most common fractures in patients with osteoporosis [1-3] (Figure 1). The World Health Organization considers osteoporosis a critical health problem among general population; it is second only to cardiovascular diseases [4]. The prevalence of osteoporosis in Italy is among $23 \%$ in women ( $45 \%$ from 70 to 79 years old or more), and almost $15 \%$ in men; thus, it is supposed that about 4 million Italian women and 800.000 men are affected by osteoporosis $[5,6]$.

The European Vertebral Osteoporosis Study reported that about $12 \%$ of people from 50 to 80 years old present vertebral deformities on imaging, with about 1.4 million of new vertebral fractures dues to osteoporosis each year; a recent study presents an estimated number

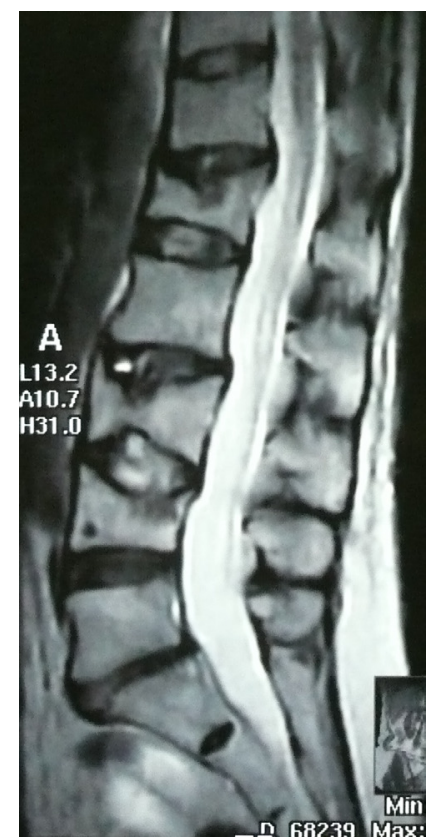

Figure 1: The CT scan showing vertebral fractures of the lumbar spine in a 72 years old woman affected by osteoporosis. of vertebral fractures in Italian people aged from 40 to 100 years old: during the year 2004 they were 58.987, 59.116 in 2005, and 60.880 in 2006 , with a $+3.1 \%$ each year [7-9]. However, it is difficult to assess the real incidence of vertebral fractures among the general population: seen that vertebral fractures can be asymptomatic ( $50 \%$ of cases) or produce non-specific symptoms, such as back pain, the biggest part (about $70 \%)$ of vertebral fractures never comes to clinical attention [10]. The hospitalization rates of patients with vertebral fractures in Italy between 2004 and 2006 were 27.6\% [11]. Symptoms such as constant back pain and physical limitations following a vertebral fracture are referred by about $40 \%$ of patients [12]. The failure of the anterior column of the vertebral body causes the wedge deformity and the resulting spine deformity in kyphosis, that can reduce the pulmonary function $[5,13]$. Symptoms and deformities can interfere with normal day activities and decrease the health-related quality of life [12,14-16].

Vertebral fractures should be treated when painful and to avoid complications and deformities [17]. Patients with a previous vertebral fracture present a higher risk of subsequent osteoporotic fractures, especially during the first year, and an increased risk of mortality until $23 \%$, with an expectation of life in 5 years reduced of $16 \%$ [5,18-21].With a world that took to an aging population, the incidence of osteoporosis and consequently of vertebral fractures is predicted to increase [12].

The aim of this study was to review the treatment of osteoporotic vertebral fractures, about conservative management, vertebroplasty and kyphoplasty.

\section{Vertebral fractures treatment}

A comprehensive search of PubMed, Medline and Google Scholar was performed; various combinations of the keywords as vertebral

${ }^{*}$ Corresponding author: Antonio Moroni, School of Sports Science, University of Bologna, Via G.C. Pupilli, 1 Bologna 40136, Italy, Tel: 0039514201911; E-mail: antonio.moroni@unibo.it

Received February 21, 2014; Accepted March 22, 2014; Published March 28 2014

Citation: Moroni A (2014) An Overview on the Approaches to Osteoporotic Vertebral Fractures Management. J Osteopor Phys Act 2: 114. doi:10.4172/23299509.1000114

Copyright: (c) 2014 Moroni A. This is an open-access article distributed under the terms of the Creative Commons Attribution License, which permits unrestricted use, distribution, and reproduction in any medium, provided the original author and source are credited. 
fractures, osteoporosis, conservative management, kyphoplasty, vertebroplasty, cementoplasty were used. A total of over 1500 citations were obtained and more papers were obtained from the references of the studies which were studied. We included articles with relief, extracted from important journals, recent (expect about bracing because more relevant articles are a little timeworn), with large series, and presenting comparisons between two techniques. Exclusion criteria were case reports, non relevant articles, non relevant journals, little series. A total of 47 studies were finally reviewed.

\section{Conservative treatment}

Conservative treatment for vertebral fractures consists in bed rest, analgesics, Non-Steroidal Anti-Inflammatory Drugs (NSAIDs), braces and rehabilitation; but the duration of each of them is not clear in literature $[1,3,17]$.

Bed rest: Bed rest should be advised only in the acute phase during some days, for not reducing muscles activity and increase osteoporosis [22].

Drugs: NSAIDs are indicated to treat pain, but complications are widely reported in literature: abdominal pain, diarrhea, increase of $47 \%$ of cardiovascular risk, and above all gastrointestinal injuries, that lead to 16.000 deaths in USA [17,23-25]. Gastrointestinal risk is reduced by the use of selective Cyclooxygenase-2 Drugs (COX-2), but cardiovascular risk is increased [26-28].

Muscle relaxants can be useful in treating muscles spasms during the acute phase and, in associations with NSAIDs, in stopping the cycle of pain, but complications such as drowsiness are reported [29,30].

Strong pain can be controlled by analgesics: paracetamol is preferred to opioids because of the risk of the reduction of gastrointestinal motility, urinary retention and cognitive deficiency that can lead to serious problems in aged patients [31].

Drugs for treating osteoporosis appear to have some effects in relief of pain too, and always have to be indicated in case of osteoporotic fractures [3].

Braces: Braces have to be indicated for vertebral fractures, but no consensus about type and length of brace wearing is reported in the literature, however, it should be up to 6 months $[17,32]$.

The goal for using a brace is: to reduce pain, bed rest inactivity, and secondary deformities; thus, they have to be comfortable, easy to put on, light, made with pressures, pads, chairback, in hyperextension position; braces don't have to be too rigid (it should lead to stiffness, limitation of movement and normal respiration) [17,32-34]. Several brace models have been designed, but some limitations are reported: Jewett and cruciform anterior spinal hyperextension braces don't permit the complete control on spine movement on coronal and transverse planes, and the Knight-Taylor brace on axial plane and dynamic balance [17]. A moulded in hyperextension plastic thoracolumbar orthosis appeared to be the best design $[33,35]$.

Rehabilitation: Rehabilitation has many reported benefits; it has to be composed by proprioceptive and extensor muscles strengthening programs, and has the scope to reduce osteoporosis, the risk of successive vertebral fractures and of secondary deformities in hyperkyphosis, to improve physical function and the subsequence quality of life [3639]. Effectiveness of rehabilitation is reported between 10 weeks and 6 months [39].

Pain relief after conservative treatment is reported between 4 weeks and 8 months $[1,16]$. No differences in pain relief (by using the Visual Analogic Scale [VAS]) between conservative and surgical treatment were seen at 3 month by Rousing et al. [40], 6 months by Shen et al. [41], Diamond et al. [42] and Alvarez et al. [43], and 12 months by Nakano et al. [44] and by Wardlaw et al. [7]. However, some residual pain can be present in patient after conservative management of vertebral fracture $[1,16]$.

Improvement in physical function (by using the Short-FormHealth Survey 36 [SF-36] score) is reported by Wardlaw in $95 \%$ of vertebral fractures conservatively treated, and at 1 year it was similar to that obtained surgically [7]. No differences in function improvement (by using the Roland Morris Disability Questionnaire [RMDQ]) and return to work activities between conservative and surgical treatment were seen at an average last follow-up of 4 years [41].

However, by conservative treatment, the restoration of vertebral body height cannot be achieved and the risk of secondary deformity in kyphosis cannot be reduced $[3,45]$.

\section{Surgical treatment}

Surgery for treating osteoporotic vertebral fractures usually consists in percutaneous minimally invasive procedures: vertebroplasty and kyphoplasty.

The purposes of surgical treatment are the rapid relief of pain, the restore of the vertebral body height and the prevention of the kyphosis deformity $[1,3]$.

Surgical procedures are associated with higher risks of complications and costs than conservative management [46], but today, with better control of patients comorbidities and reduced complication rates, surgery produces high satisfactions with acceptably risks $[1,3]$, and it can be an alternative treatment for people that can't manage braces [17].

Earlier relief in VAS after surgical treatment is reported in 1 month [41]. Moreover, kyphosis are quite well controlled by surgical procedure: from an average value of $12.8^{\circ}$ to $11^{\circ}$, but it seems that there is no relation between kyphosis magnitude and pain [46].

\section{Vertebroplasty}

Vertebroplasty is a percutaneous minimally invasive procedure, that was first performed in France in 1985 for treating vertebral angiomas [47]. To perform a vertebroplasty, a bone needle is passed through or lateral unilateral or bilateral pedicles until the vertebral body and a small amount of cement of Polymethylmethacrylate (PMMA) or Calcium phosphate-based, mixed with antibiotic and barium or tantalum is pushed into. Once injected, the cement hardens quickly. The procedure is monitored by fluoroscopy [1,3,44] (Figure 2).

Pain relief after vertebroplasty is reported in 24-48 hours [1], and it remains higher compared to conservative management until from 6 weeks [3,47-50] to 13 months [51,52]. Several studies reported the relief of pain after vertebroplasty in $70-90 \%$ of cases $[1,18]$. Even if vertebroplasty is performed 3 months later the fracture when conservative treatment failed, pain relief (measured by VAS) and functional outcome (measured by the Oswestry Disability Index, [ODI]) improve significantly up to 2 years [53].

The restoration of vertebral body height can be achieved by vertebroplasty [51], especially in fresh fractures $[3,54]$.

One of the most common complications of vertebroplasty is the leakage of the cement, until $65 \%$ of cases $[1,3,52,55]$, with symptoms in only $1.1-3 \%$ of them $[47,56]$. Cement can leak to the peridural space or 
Citation: Moroni A (2014) An Overview on the Approaches to Osteoporotic Vertebral Fractures Management. J Osteopor Phys Act 2: 114. doi:10.4172/2329-9509.1000114

Page 3 of 6

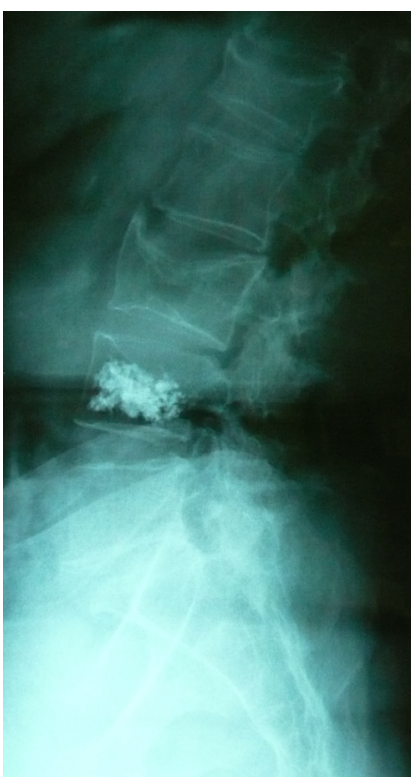

Figure 2: A lumbar osteoporotic vertebral fracture in a 75 years old woman treated with vertebroplasty: the body is filled of PMMA, antibiotic and barium during a fluoroscoply-controled procedure.

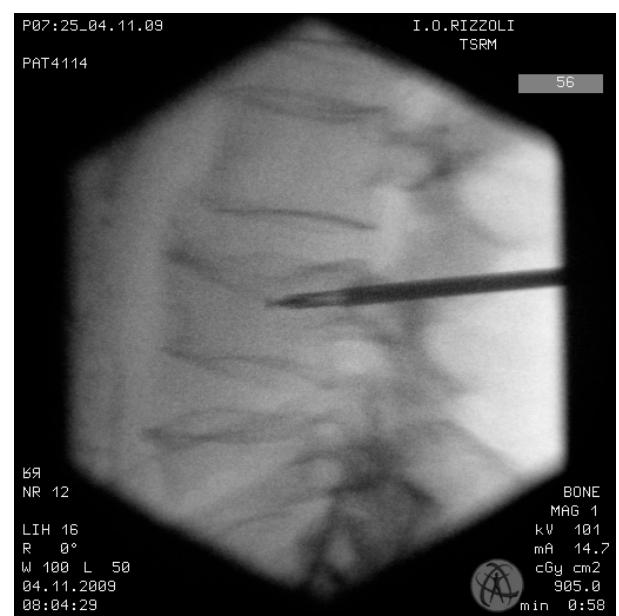

Figure 3a: A lumbar osteoporotic vertebral fracture in a 77 years old woman treated with kyphoplasty: during fluoroscopy, a cannula is inserted into the vertebral body.

to vertebral venous system, and it can produce radiculopathies (4\% of cases), spinal cord injuries $(<0.5 \%$ of cases) $[47,55,57,58]$, pulmonary or cerebral embolism $[1,59]$. Other general complications are reported from 2.4 to $4.8 \%$ of cases $[56,60]$.

Baroud et al. reported an inward bulge up to $17 \%$ of the endplate adjacent to the one augmented after vertebroplasty that may be cause fractures [61]; adjacent vertebral fractures were seen by Lovi in $1.3 \%$ of cases [53], by Schofer in 3.3\% [52] and by Grohs in 4.3\% [62]; others papers reported non-significant differences with conservative treatment $[40,42]$. New vertebral fractures were reported in $1.3 \%$ of patients by Lovi [53].

Even if vertebroplasty is associated with higher costs than conservative management, the Ratio cost-effective is higher [46,54].

\section{Kyphoplasty}

Kyphoplasty is a percutaneous minimally invasive procedure. Patient is positioned in the hyperlordotic position; a little cannula is inserted until the vertebral body, and a balloon catheter is passed through it; afterwards, it is blown to increase the collapsed space and to create a defined cavity, that is then filled of the cement [1,63-65] (Figure 3a-c).

Several studies reported the relief of pain until $90 \%$ of cases $[1,2,18,52]$, that is gained in $24-48$ hours [1], and sustained up to 2 years follow-up $[51,62]$, with a subsequence reduction of drugs necessity during the first 6 months [7].

Improvement in physical function (by SF-36 score) is reported by Lieberman et al. [2], by Kasperk et al. [66], and by Wardlaw et al. in $95 \%$ of cases (improvement of $28.3 \%$ at 1 month, versus $6.4 \%$ in the conservative treated control group) [7].

Pain relief (as measured by the VAS) and functional outcome (as measured by the ODI) improve significantly up to 2 years, even if kyphoplasty is performed 1 months later the trauma, when conservative treatment failed [53].

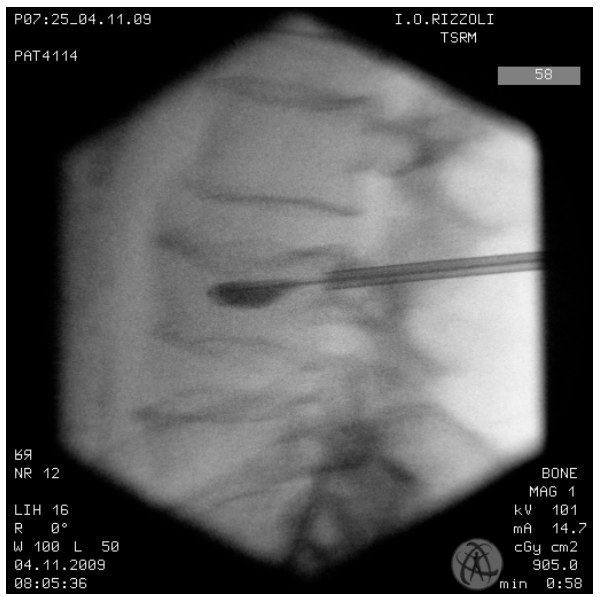

Figure 3b: A ballon catheter is passed through the cannula into the vertebra (?) body, then it is blown to increase the collapsed space and to create a defined cavity.

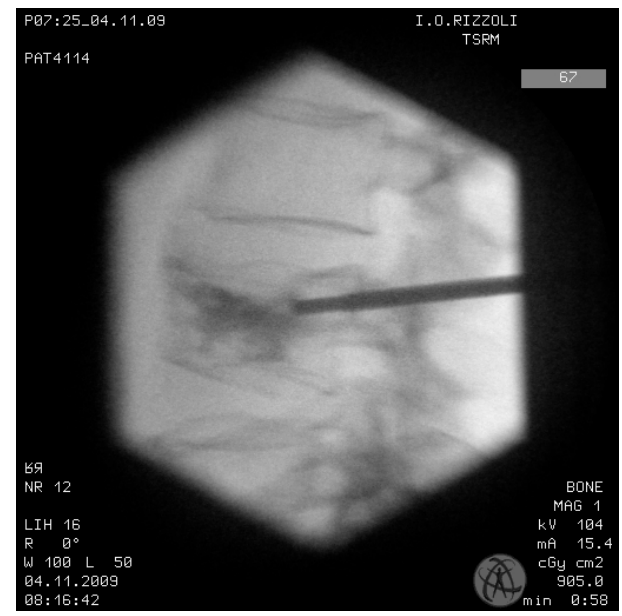

Figure 3c: The cavity is filled with PMMA, antibiotic and barium. 
Restoration of the vertebral body height is achieved in $47 \%$ of cases $[2,51]$, higher than in vertebroplasty procedures [51]; at postoperative time, restoration is up to $15.4 \%$, remaining stable up to 3 years followup $[53,66]$. The control of the vertebral body height reduces the risk of secondary spine deformity in kyphosis $[51,66]$.

New vertebral fractures were seen in $33 \%$ of cases at 1 year in a few studies [6], adjacent vertebral fractures were seen by Liu et al. in $4 \%$ of patients [51] and by Grohs et al. in $21.4 \%$ [62], but other studies reported no new or adjacent fractures [53,67].

Patients operated by kyphoplasty can return to daily activities faster than conservative treated patients, with a difference of 60 days as reported by Wardlaw et al. [7]. Wardlaw et al. also reported an improvement of quality of life as measured by SF-36 physical component summary scale, Euro QOL-5D quality-of-life questionnaire and RMDQ at 1 month until 3 years [7].

Complications after kyphoplasty were seen in $0.8 \%$ of 360 consecutive procedures by Majd et al. [68]. Cement leakage is less frequent after kyphoplasty procedure, because of the major cement viscosity $[1,18]$; the rate is reported form $6.6 \%$ to $27 \%$, and all cases were asymptomatic $[2,7,45,52]$.

No differences between kyphoplasty and vertebroplasty were seen in the assessment of pain (VAS) and function (ODI) at 2 years followup by Grohs et al. [62]. Schofer et al. reported a better reduction of kyphosis after kyphoplasty then vertebroplasty [52]. Lovi et al. reported a longer surgical time and bigger quantity of used PMMA after kyphoplasty then vertebroplasty [51,53].

Kyphoplasty is associated with higher costs than conservative management, but the Ratio cost-effective is higher [67].

\section{Conclusions}

No differences in pain relief after conservative or surgical treatment was seen over time; this means that the same result can be reached by the two procedures. Considering that the surgical treatment has higher risks, although limited, and higher costs, conservative management should be preferably indicated. However, agreement is reported in literature about short-term benefits of surgical treatment in terms of relief of pain, improved vertebral body height, physical function and quality of life; the rate cost-effective for vertebroplasty and kyphoplasty is definitely higher. Vertebroplasty presents more risks of complications then kyphoplasty; kyphoplasty is the best procedure to regain the height vertebral body and to control kyphosis, but longer surgical time is seen; thus, kyphoplasty should be better indicated in younger people with higher functional demands. The risk of subsequent vertebral fractures have not been clearly demonstrated by literature after the three procedures; referral physicians should be aware patients about this risk, and a focused osteoporosis therapy should be indicated.

Several limitations in comparing studies about choosing conservative or surgical treatment in osteoporotic vertebral fractures have been found, especially because of the big difference in number of patients and clinical scores, and the little sham-controlled studies.

\section{References}

1. Moroni A, Hoang-Kim A, Micera G, Gelsomini L, Orsini R, et al. (2009) Surgica Management of Osteoporotic Vertebral Fractures. Adv Orthop 1: 93-96.

2. Lieberman IH, Dudeney S, Reinhardt MK, Bell G (2001) Initial outcome and efficacy of "kyphoplasty" in the treatment of painful osteoporotic vertebral compression fractures. Spine (Phila Pa 1976) 26: 1631-1638.
3. Boonen S, Wahl DA, Nauroy L, Brandi ML, Bouxsein ML, et al. (2011) Balloon kyphoplasty and vertebroplasty in the management of vertebral compression fractures. Osteoporos Int 22: 2915-2934.

4. Kanis JA, Burlet N, Cooper C, Delmas PD, Reginster JY, et al. (2008) European guidance for the diagnosis and management of osteoporosis in postmenopausal women. Osteoporos Int 19: 399-428.

5. Deyo RA, Cherkin DC, Loeser JD, Bigos SJ, Ciol MA (1992) Morbidity and mortality in association with operations on the lumbar spine. The influence of age, diagnosis, and procedure. J Bone Joint Surg Am 74: 536-543.

6. Kanis JA, Johnell O, De Laet C, Johansson H, Oden A, et al. (2004) A metaanalysis of previous fracture and subsequent fracture risk. Bone 35: 375-382.

7. Wardlaw D, Cummings SR, Van Meirhaeghe J, Bastian L, Tillman JB, et al. (2009) Efficacy and safety of balloon kyphoplasty compared with non-surgical care for vertebral compression fracture (FREE): a randomised controlled trial. Lancet 373: 1016-1024.

8. European Prospective Osteoporosis Study (EPOS) Group, Felsenberg D, Silman AJ, Lunt M, Armbrecht G, et al. (2002) Incidence of vertebral fracture in europe: results from the European Prospective Osteoporosis Study (EPOS). J Bone Miner Res 17: 716-724.

9. Piscitelli P, Brandi ML, Chitano G, Argentiero A, Neglia C, et al. (2011) Epidemiology of fragility fractures in Italy. Clin Cases Miner Bone Metab 8: 2934.

10. Cummings SR, Melton LJ (2002) Epidemiology and outcomes of osteoporotic fractures. Lancet 359: 1761-1767.

11. Tarantino U, Capone A, Planta M, D'Arienzo M, Letizia Mauro G, et al. (2010) The incidence of hip, forearm, humeral, ankle, and vertebral fragility fractures in Italy: results from a 3-year multicenter study. Arthritis Res Ther 12: R226.

12. Scane AC, Sutcliffe AM, Francis RM (1994) The sequelae of vertebral crush fractures in men. Osteoporos Int 4: 89-92.

13. Schlaich C, Minne HW, Bruckner T, Wagner G, Gebest HJ, et al. (1998) Reduced pulmonary function in patients with spinal osteoporotic fractures. Osteoporos Int 8: 261-267.

14. Ettinger B, Black DM, Nevitt MC, Rundle AC, Cauley JA, et al. (1992) Contribution of vertebral deformities to chronic back pain and disability. The Study of Osteoporotic Fractures Research Group. J Bone Miner Res 7: 449 456.

15. Cockerill W, Lunt M, Silman AJ, Cooper C, Lips P, et al. (2004) Health-related quality of life and radiographic vertebral fracture. Osteoporos Int 15: 113-119.

16. Silverman SL (1992) The clinical consequences of vertebral compression fracture. Bone 13 Suppl 2: S27-31.

17. Longo UG, Loppini M, Denaro L, Maffulli N, Denaro V (2012) Conservative management of patients with an osteoporotic vertebral fracture: a review of the literature. J Bone Joint Surg Br 94: 152-157.

18. Notelovitz M (2003) Osteoporosis: Prevention, Diagnosis and Management (5th Edn.), Professional Communications, New York, NY, USA.

19. Pongchaiyakul C, Nguyen ND, Jones G, Center JR, Eisman JA, et al. (2005) Asymptomatic vertebral deformity as a major risk factor for subsequent fractures and mortality: a long-term prospective study. J Bone Miner Res 20: 1349-1355

20. Lindsay R, Silverman SL, Cooper C, Hanley DA, Barton I, et al. (2001) Risk of new vertebral fracture in the year following a fracture. JAMA 285: 320-323.

21. Cooper C, Atkinson EJ, Jacobsen SJ, O'Fallon WM, Melton LJ 3rd (1993) Population-based study of survival after osteoporotic fractures. Am J Epidemiol 137: 1001-1005.

22. Krølner B, Toft B (1983) Vertebral bone loss: an unheeded side effect of therapeutic bed rest. Clin Sci (Lond) 64: 537-540.

23. Roelofs PD, Deyo RA, Koes BW, Scholten RJ, van Tulder MW (2008) Nonsteroidal anti-inflammatory drugs for low back pain: an updated Cochrane review. Spine (Phila Pa 1976) 33: 1766-1774.

24. Bavry AA, Khaliq A, Gong Y, Handberg EM, Cooper-Dehoff RM, et al. (2011) Harmful effects of NSAIDs among patients with hypertension and coronary artery disease. Am J Med 124: 614-620.

25. Tarone RE, Blot WJ, McLaughlin JK (2004) Nonselective nonaspirin nonsteroidal anti- inflammatory drugs and gastrointestinal bleeding: relative and absolute risk esti- mates from recent epidemiologic studies. Am J Ther 11: $17-25$ 
Citation: Moroni A (2014) An Overview on the Approaches to Osteoporotic Vertebral Fractures Management. J Osteopor Phys Act 2: 114 doi:10.4172/2329-9509.1000114

26. Moore RA, Derry S, Makinson GT, McQuay HJ (2005) Tolerability and adverse events in clinical trials of celecoxib in osteoarthritis and rheumatoid arthritis: systematic review and meta-analysis of information from company clinical trial reports. Arthritis Res Ther 7: R644-R665.

27. Silverstein FE, Faich G, Goldstein JL, Simon LS, Pincus T, et al. (2000) Gastrointestinal toxicity with celecoxib vs nonsteroidal anti-inflammatory drugs for osteoarthritis and rheumatoid arthritis: the CLASS study: A randomized controlled trial. Celecoxib Long-term Arthritis Safety Study. JAMA 284: 12471255.

28. Kearney PM, Baigent C, Godwin J, Halls H, Emberson JR, et al. (2006) Do selective cyclo-oxygenase-2 inhibitors and traditional non-steroidal antiinflammatory drugs increase the risk of atherothrombosis? Meta-analysis of randomised trials. BMJ 332: 1302-1308.

29. Browning R, Jackson JL, O'Malley PG (2001) Cyclobenzaprine and back pain a meta-analysis. Arch Intern Med 161: 1613-1620.

30. van Tulder MW, Touray T, Furlan AD, Solway S, Bouter LM (2003) Muscle relaxants for non-specific low back pain. Cochrane Database Syst Rev : CD004252.

31. Cherasse A, Muller G, Ornetti P, Piroth C, Tavernier C, et al. (2004) Tolerability of opioids in patients with acute pain due to nonmalignant musculoskeletal disease. A hospital-based observational study. Joint Bone Spine 71: 572-576.

32. Prather H, Watson JO, Gilula LA (2007) Nonoperative management of osteoporotic vertebral compression fractures. Injury 38 Suppl 3: S40-48.

33. Buchalter D, Kahanovitz N, Viola K, Dorsky S, Nordin M (1988) Threedimensional spinal motion measurements. Part 2: A noninvasive assessment of lumbar brace immobilization of the spine. J Spinal Disord 1: 284-286.

34. Cholewicki J, Lee AS, Peter Reeves N, Morrisette DC (2010) Comparison of trunk stiffness provided by different design characteristics of lumbosacral orthoses. Clin Biomech (Bristol, Avon) 25: 110-114.

35. Lantz SA, Schultz AB (1986) Lumbar spine orthosis wearing. II. Effect on trunk muscle myoelectric activity. Spine (Phila Pa 1976) 11: 838-842.

36. Sinaki M, Itoi E, Wahner HW, Wollan P, Gelzcer R, et al. (2002) Stronger back muscles reduce the incidence of vertebral fractures: a prospective 10 year follow-up of postmenopausal women. Bone 30: 836-841.

37. Sinaki M, Lynn SG (2002) Reducing the risk of falls through proprioceptive dynamic posture training in osteoporotic women with kyphotic posturing: a randomized pilot study. Am J Phys Med Rehabil 81: 241-246.

38. Sinaki M, Brey RH, Hughes CA, Larson DR, Kaufman KR (2005) Significant reduction in risk of falls and back pain in osteoporotic-kyphotic women through a Spinal Proprioceptive Extension Exercise Dynamic (SPEED) program. Mayo Clin Proc 80: 849-855.

39. Malmros B, Mortensen L, Jensen MB, Charles P (1998) Positive effects of physiotherapy on chronic pain and performance in osteoporosis. Osteoporos Int 8: 215-221.

40. Rousing R, Hansen KL, Andersen MO, Jespersen SM, Thomsen K, et al (2010) Twelve-months follow-up in forty-nine patients with acute/semiacute osteoporotic vertebral fractures treated conservatively or with percutaneous vertebroplasty: a clinical randomized study. Spine (Phila Pa 1976) 35: 478-482.

41. Shen WJ, Liu TJ, Shen YS (2001) Nonoperative treatment versus posterior fixation for thoracolumbar junction burst fractures without neurologic deficit Spine (Phila Pa 1976) 26: 1038-1045

42. Diamond TH, Bryant C, Browne L, Clark WA (2006) Clinical outcomes after acute osteoporotic vertebral fractures: a 2-year non-randomised trial comparing percutaneous vertebroplasty with conservative therapy. Med J Aust 184: 113117.

43. Alvarez L, Alcaraz M, Pérez-Higueras A, Granizo JJ, de Miguel I, et al. (2006) Percutaneous vertebroplasty: functional improvement in patients with osteoporotic compression fractures. Spine (Phila Pa 1976) 31: 1113-1118.

44. Nakano M, Hirano N, Ishihara H, Kawaguchi $\mathrm{Y}$, Watanabe H, et al. (2006) Calcium phosphate cement-based vertebro- plasty compared with conservative treatment for osteoporotic compression fractures: a matched case-control study. J Neurosurg Spine 4:110-117.

45. Kasperk C, Hillmeier J, Noldge G, Grafe IA, DaFonseca K, et al. (2005) Treatment of painful vertebral fractures by kyphoplasty in patients with primary osteoporosis: a prospective nonrandomized controlled study. J Bone Miner Res 20: $604-612$
46. Gnanenthiran SR, Adie S, Harris IA (2012) Nonoperative versus operative treatment for thoracolumbar burst fractures without neurologic deficit: a metaanalysis. Clin Orthop Relat Res 470: 567-577.

47. Hulme PA, Krebs J, Ferguson SJ, Berlemann U (2006) Vertebroplasty and kyphoplasty: a systematic review of 69 clinical studies. Spine (Phila Pa 1976) 31: 1983-2001

48. McGirt MJ, Parker SL, Wolinsky JP, Witham TF, Bydon A, et al. (2009) Vertebroplasty and kyphoplasty for the treatment of vertebral compression fractures: an evidenced-based review of the literature. Spine J 9: 501-508.

49. Hochmuth K, Proschek D, Schwarz W, Mack M, Kurth AA, et al. (2006) Percutaneous vertebroplasty in the therapy of osteoporotic vertebral compression fractures: a critical review. Eur Radiol 16: 998-1004.

50. Gill JB, Kuper M, Chin PC, Zhang Y, Schutt R Jr (2007) Comparing pain reduction following kyphoplasty and vertebroplasty for osteoporotic vertebral compression fractures. Pain Physician 10: 583-590.

51. Liu JT, Liao WJ, Tan WC, Lee JK, Liu CH, et al. (2009) Balloon kyphoplasty versus vertebroplasty for treatment of osteoporotic vertebral compression fracture: a prospective, comparative, and randomized clinical study. Osteoporos Int 21: 359-364.

52. Schofer MD, Efe T, Timmesfeld N, Kortmann HR, Quante M (2009) Comparison of kyphoplasty and vertebroplasty in the treatment of fresh vertebral compression fractures. Arch Orthop Trauma Surg 129: 1391-1399.

53. Lovi A, Teli M, Ortolina A, Costa F, Fornari M, et al. (2009) Vertebroplasty and kyphoplasty: complementary techniques for the treatment of painful osteoporotic vertebral compression fractures. A prospective non-randomised study on 154 patients. Eur Spine J 18: S95-S101.

54. Masala S, Ciarrapico AM, Konda D, Vinicola V, Mammucari M, et al. (2008) Cost-effectiveness of percutaneous vertebroplasty in osteoporotic vertebral fractures. Eur Spine J 17: 1242-1250.

55. Cortet B, Cotten A, Boutry N, Flipo RM, Duquesnoy B, et al. (1999) Percutaneous vertebroplasty in the treatment of osteoporotic vertebral compression fractures: an open prospective study. J Rheumatol 26: 2222-2228.

56. Lee MJ, Dumonski M, Cahill P, Stanley T, Park D, et al. (2009) Percutaneous treatment of vertebral compression fractures: a meta-analysis of complications. Spine (Phila Pa 1976) 34: 1228-1232.

57. Chiras J, Depriester C, Weill A, Sola-Martinez MT, Deramond H (1997) [Percutaneous vertebral surgery. Technics and indications]. J Neuroradiol 24 $45-59$.

58. McCall T, Cole C, Dailey A (2008) Vertebroplasty and kyphoplasty: a comparative review of efficacy and adverse events. Curr Rev Musculoskele Med 1: 17-23.

59. Groen RJ, du Toit DF, Phillips FM, Hoogland PV, Kuizenga K, et al. (2004) Anatomical and pathological considerations in percutaneous vertebroplasty and kyphoplasty: a reappraisal of the vertebral venous system. Spine (Phila Pa 1976) 29: 1465-1471.

60. Ploeg WT, Veldhuizen AG, The B, Sietsma MS (2006) Percutaneous vertebroplasty as a treatment for osteoporotic vertebral compression fractures: a systematic review. Eur Spine J 15: 1749-1758.

61. Baroud G, Nemes J, Heini P, Steffen T (2003) Load shift of the intervertebra disc after a vertebroplasty: a finite-element study. Eur Spine J 12: 421-426.

62. Grohs JG, Matzner M, Trieb K, Krepler P (2005) Minimal invasive stabilization of osteoporotic vertebral fractures: a prospective nonrandomized comparison of vertebroplasty and balloon kyphoplasty. J Spinal Disord Tech 18: 238-242.

63. Voggenreiter G (2005) Balloon kyphoplasty is effective in deformity correction of osteoporotic vertebral compression fractures. Spine (Phila Pa 1976) 30 2806-2812.

64. Phillips FM, Todd Wetzel F, Lieberman I, Campbell-Hupp M (2002) An in vivo comparison of the potential for extravertebral cement leak after vertebroplasty and kyphoplasty. Spine (Phila Pa 1976) 27: 2173-2178.

65. Grafe IA, Da Fonseca K, Hillmeier J, Meeder PJ, Libicher M, et al. (2005) Reduction of pain and fracture incidence after kyphoplasty: 1-year outcomes of a prospective controlled trial of patients with primary osteoporosis. Osteoporos Int 16: 2005-2012.

66. Kasperk C, Grafe IA, Schmitt S, Nöldge G, Weiss C, et al. (2010) Three-year outcomes after kyphoplasty in patients with osteoporosis with painful vertebral fractures. J Vasc Interv Radiol 21: 701-709. 
Citation: Moroni A (2014) An Overview on the Approaches to Osteoporotic Vertebral Fractures Management. J Osteopor Phys Act 2: 114. doi:10.4172/2329-9509.1000114

Page 6 of 6

67. Taylor RS (2008) Cost-effectiveness of balloon kyphoplasty for symptomatic vertebral compression fractures in osteoporotic patients. Osteoporos Int 19: S51.
68. Majd ME, Farley S, Holt RT (2005) Preliminary outcomes and efficacy of the first 360 consecutive kyphoplasties for the treatment of painful osteoporotic vertebral compression fractures. Spine J 5: 244-255.
Submit your next manuscript and get advantages of OMICS Group submissions

\section{Unique features:}

- User friendly/feasible website-translation of your paper to 50 world's leading languages

- Audio Version of published paper

- Digital articles to share and explore

Special features:

- 300 Open Access Journals

25,000 editorial team

21 days rapid review process

- Quality and quick editorial, review and publication processing

- Indexing at PubMed (partial), Scopus, EBSCO, Index Copernicus and Google Scholar etc

Sharing Option: Social Networking Enabled

- Authors, Reviewers and Editors rewarded with online Scientific Credits

- Better discount for your subsequent articles

Submit your manuscript at: http://www.omicsonline.org/submission/ ation: Moroni A (2014) An Overview on the Approaches to Osteoporotic Vertebral Fractures Management. J OsteoporPhys Act 2: 114. doi:10.4172/23299509.1000114 